Research Article

\title{
Effect of Residual Stress on the Mechanical Properties of FSW Joints with SUS409L
}

\author{
Yeong-Seok Lim, ${ }^{1,2}$ Sang-Hyuk Kim, ${ }^{3}$ and Kwang-Jin Lee ${ }^{1}{ }^{1}$ \\ ${ }^{1}$ Carbon \& Light Materials Application Group, Korea Institute of Industrial Technology, Jeonju, Republic of Korea \\ ${ }^{2}$ Division of Mechanical Design Engineering, Chonbuk National University, Jeonju, Republic of Korea \\ ${ }^{3}$ R\&D Center, Daewoo Industrial, Anyang, Republic of Korea
}

Correspondence should be addressed to Kwang-Jin Lee; kjlee@kitech.re.kr

Received 21 August 2017; Accepted 16 November 2017; Published 3 April 2018

Academic Editor: Akihiko Kimura

Copyright (c) 2018 Yeong-Seok Lim et al. This is an open access article distributed under the Creative Commons Attribution License, which permits unrestricted use, distribution, and reproduction in any medium, provided the original work is properly cited.

\begin{abstract}
This study was performed to investigate both the residual stress distribution and the effect of the residual stress formed at the welding region on the mechanical properties of the friction stir welded joints with 409L stainless steel sheets. Residual stress measurement with hole-drilling method; mechanical property evaluation including tensile test, Charpy impact test, and fatigue test; and microstructure observation were conducted. It has got no residual stresses to speak of at the center region of the stir zone because the stored stresses are released in the process of the dynamic recrystallization, while a small quantity of compressive residual stresses is formed at the surface region of the stir zone because of strong compression reaction by the tool shoulder. A considerable amount of compressive residual stresses is formed at the thermomechanical affected zone because of the synergy between the thermal expansion due to the heat conduction from the stir zone and mechanical compression by the tool. The formation of residual stresses shows a similar tendency between the advancing side and the retreating side. Both the mitigation of residual stress in the stir zone and the formation of compressive residual stress in the thermomechanical affected zone contribute to the improvement of the mechanical properties of the friction stir welded joints.
\end{abstract}

\section{Introduction}

When the materials are welded by conventional fusion welding methods such as tungsten inert gas (TIG) welding, metal inert gas (MIG) welding, and laser welding, several kinds of defect such as solidification cracks, elemental segregation, and brittle phases are generally formed due to melting and solidification reactions in the welds during the welding process. These defects significantly degrade the mechanical properties of the welds [1-9]. Residual stress formed at the welding region is one of the most important parameters determining the mechanical properties of the welds $[10,11]$. Anastassiou et al. reported that residual stresses in the welding region decrease the fatigue and fracture strength of the welds manufactured by the spot welding process [12]. They found that minimum welding residual stresses were achieved by selecting appropriate welding parameters. Nevertheless, conventional fusion welding processes have been generally documented to result in high residual stress and hence poor mechanical properties of the joints. The initial development of friction stir welding (FSW) was focused on the welding of aluminum alloys $[13,14]$. The solid-state process of FSW leads to a number of benefits in terms of the mechanical and metallurgical properties of the joints. With these benefits, FSW has found applications in various industries for joining a variety of materials $[15,16]$. In these days, this technology has only recently been adapted for joining stainless steels. Although some studies [17-19] investigated residual stress in the aluminum alloys welded by FSW, none have focused on the residual stress in stainless steels or on the relation between residual stresses and mechanical properties in stainless steels. In the present study, friction stir welding was performed to investigate both the formation of the residual stresses at the welding region and 
TABLE 1: Chemical composition of SUS 409L stainless steel sheets used in this study (mass \%).

\begin{tabular}{lcccccccc}
\hline $\mathrm{C}$ & $\mathrm{Si}$ & $\mathrm{Mn}$ & $\mathrm{Cr}$ & $\mathrm{Ni}$ & $\mathrm{V}$ & $\mathrm{Ti}$ & Others & $\mathrm{Fe}$ \\
\hline 0.01 & 0.54 & 0.20 & 11.64 & 0.26 & 0.08 & 0.25 & 0.09 & Bal. \\
\hline
\end{tabular}

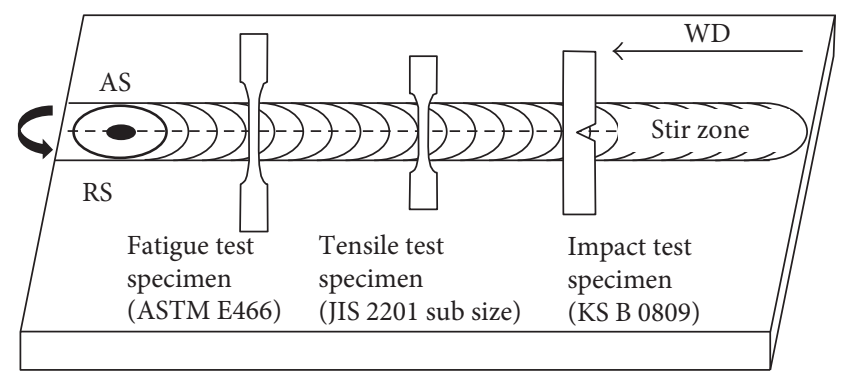

Figure 1: Schematic illustration of the friction stir welding process and test specimens.

its effect on the mechanical properties of the joints with SUS 409L sheets. The distribution of the residual stresses developed at various welding regions was quantitatively measured by a hole-drilling method. The formation behavior of the residual stresses at each welding region was also discussed. Effects of residual stress on mechanical properties such as impact and fatigue properties were precisely investigated.

\section{Experimental Procedures}

The chemical composition of SUS 409L stainless steel sheets used in the present study is listed in Table 1 . The welding specimens were prepared with $400 \mathrm{~mm}$ (length) $\times 150 \mathrm{~mm}$ (width) $\times 2 \mathrm{~mm}$ (thickness). FSW was conducted at a tool rotational speed of $800 \mathrm{RPM}$ and traveling speed of $250 \mathrm{~mm} / \mathrm{min}$ with a convex type PCBN tool having a probe diameter of $5.5 \mathrm{~mm}$ and length of $1.6 \mathrm{~mm}$. The tilt angle was maintained at zero degrees. The rotating tool travelled along the butt line between the two welding specimens. Optical microscopy (OM, Olympus, GX51) and electron backscattered diffraction (EBSD) methods were selected to observe the microstructure of the welding region and base metal (BM). Specimens for OM observation were prepared by mechanical polishing using $0.5 \mu \mathrm{m}$ silica suspension followed by chemical etching using nital solution $(40 \mathrm{ml}$ $\mathrm{HNO}_{3}+60 \mathrm{ml} \mathrm{HCl}$ ). EBSD specimens were prepared by mechanical polishing followed by electrochemical polishing with a solution of $6 \%$ perchloric acid and $94 \%$ ethanol. ESBD data were obtained in a field-emission scanning electron microscope (FE-SEM, JEOL, JSM-700F, $200 \mathrm{kV}$ ) and analyzed using TSL OIM software to obtain microstructural information. Test specimens were taken from the joints according to the standard and schematically illustrated in Figure 1. Both the gage part of the tensile and fatigue test specimens and the notch of the impact specimens were placed in the center of the stir zone (SZ). Tensile tests were performed using a dynamic material test machine (Instron, 8801, $100 \mathrm{kN}$ ) with JIS 2201 subsize specimens (thickness:
$2 \mathrm{~mm}$; gage length: $30 \mathrm{~mm}$ ) at a crosshead speed of $1 \mathrm{~mm} / \mathrm{min}$. Impact tests were performed with KS B 0809 specimens (thickness: $2 \mathrm{~mm}$ ) using a Charpy impact tester (Zwick/Roell, RKP-450) with a hammer degree of $150^{\circ}$. Fatigue tests were conducted using a resonance fatigue test machine with ASTM E466 specimens (thickness: $2 \mathrm{~mm}$; gage length: $24 \mathrm{~mm}$ ). The maximum stress levels used were selected as a function of the yield stress for the FSW joint and the base metal. Values of $40 \sim 80$ percent of the yield stress were selected. A stress ratio of $R=0.1$ was applied. Fatigue life was defined as the number of cycles to failure. The number of cycles considered as a limit for infinite life was $10^{7}$ cycles. A hole-drilling method was selected for measurement of the residual stresses in the welding region. This method measures residual stress using gages, which respond to the change of electrical resistance. The value of electrical resistance changes when the residual stresses formed at the welding region are released by drilling a hole. In this study, type B gages were applied according to the ASTM E837 standard, and the holes with $2 \mathrm{~mm}$ in diameter were drilled from surface to depth direction. The residual stresses were measured at BM, SZ, TMAZ-AS, and TMAZ-RS per $0.1 \mathrm{~mm}$ drilling.

\section{Results}

3.1. Microstructure. Figure 2 shows macroscopic and microscopic cross-sectional images of the FSW joints. No macro- and micro-welding defects were found from the optical microscopic observation. The welding region of the FSW joints consisted of stir zone (SZ) and thermomechanical affected zone (TMAZ). SZ is a dynamically recrystallized region characterized by much finer grains than those of BM. Located between SZ and BM, TMAZ, unlike the $S Z$, retained a deformed and/or elongated structure along the $\mathrm{SZ}$, as is demonstrated by the EBSD analysis that is presented in Discussion. As TIG welding proceeds with melting and solidification of joint materials, a cast structure formed in FZ [6]. In contrast, only a recrystallized and deformed structure formed without a cast structure in the FSW joints because of the solid-state welding characteristic of FSW. These characteristic microstructures formed in the welded joints were considered to be closely related to residual stress evolution and their mechanical properties. The arrows in Figure 3 indicate the measurement positions of residual stress. The residual stresses were measured through the thickness direction from the joints surface up to $1 \mathrm{~mm}$ depth so that the measurement positions contained SZ and TMAZ in the joints.

3.2. Residual Stress Distribution. Residual stress measurement positions are schematically illustrated in Figure 3. Residual stress were measured at the BM, SZ, advancing side of TMAZ (TMAZ-AS), and retreating side of TMAZ (TMAZ-RS) as a function of depth from the surface of the joints. As indicated by the insert figure, TMAZ-AS and TMAZ-RS passed through both SZ and TMAZ. Figure 4 shows the residual stress distribution of the base metal 


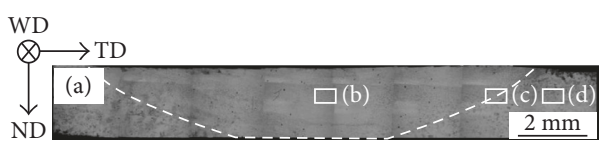

(a)

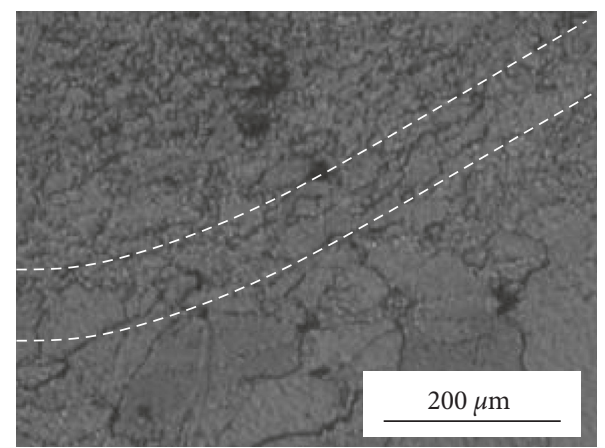

(c)

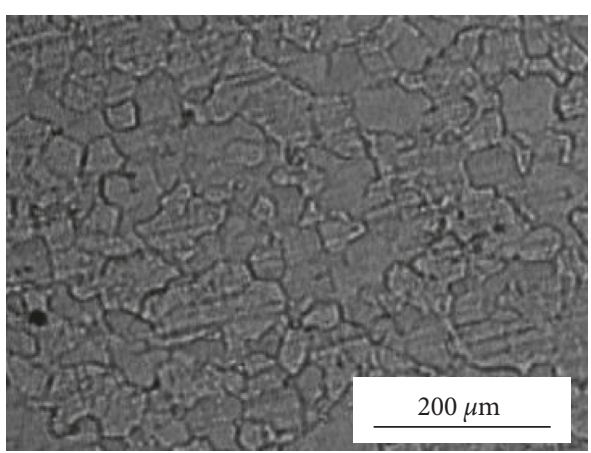

(b)

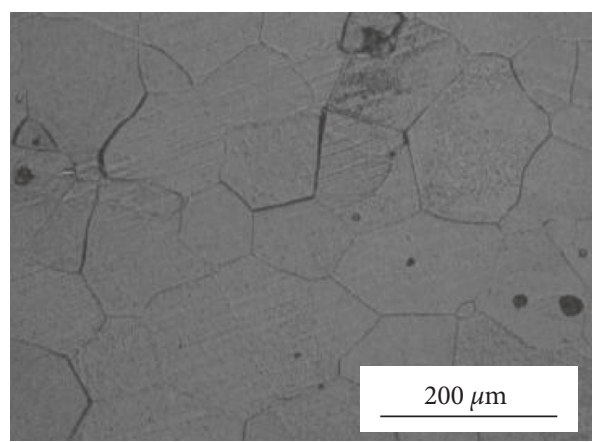

(d)

FIgURE 2: Cross-sectional optical micrographs of the joints showing (a) the overall weld region at low magnification and measurement positions of residual stress (marked by white boxes), and high-magnification images showing (b) SZ, (c) boundary region between SZ and $\mathrm{BM}$, and (d) BM.

contiguous to the welding region. Regardless of depth from the surface, residual stress of transverse direction (TD) and welding direction (WD) was nearly not found. It was considered that residual stresses involved from rolling process were removed because the base metal sheets were fully annealed at the step of heat treatment. Figure 5 shows the residual stress distribution at the stir zone of the FSW joint. Almost all areas had low tensile residual stresses. However, some degree of compressive residual stresses was measured at the surface area. It was thought to be that the convex-type tool made an effect on the formation of the compressive residual stresses at the surface area in the stir zone. The residual stresses in both TD and WD presented the same component, and the values of them were generally similar. Figures 6 and 7 show the residual stress distribution at the TMAZ-AS and TMAZ-RS, respectively. The quite distinctive results to that in the stir zone were obtained in these regions. The region corresponding to TMAZ, that is, at depths ranging from $0.7 \mathrm{~mm}$ to $0.9 \mathrm{~mm}$, expressed compressive residual stress that exceeded $200 \mathrm{MPa}$. In TMAZAS, the compressive residual stress in the WD was slightly larger than that in the TD. This trend was the same in TMAZ-RS. In addition, the compressive residual stresses measured in the TMAZ-RS region were also larger than that in the TMAZ-AS region. It was considered that these results were related to imposed force, and material flow phenomena in the welding region include SZ and TMAZ during friction stir welding. These phenomena could be explained by the previous study. The grain of the TMAZ-AS tends to exhibit more material flow characteristics than that of TMAZ-RS due to the TMAZ-RS's interaction and collision of the flow metals of TMAZ-AS and TMAZ-RS rotating in different directions. With more drastic mechanical force and higher temperature, the metal on the TMAZ-AS could flow more drastically, and grains on the AS are easily elongated and show more flowing characteristics than the TMAZ-RS [20]. In summary, it was confirmed that low level of tensile residual stress and considerable amount of compressive residual stress are formed at the center of the stir zone and at the edge of the stir zone, respectively. It is quite different from the results of the TIG joint, which generally forms tensile residual stresses in the fusion zone [6]. It was suggested that the difference in the formation of residual stress in the welding region may have an effect on the mechanical properties of the joints.

3.3. Mechanical Properties. Figure 8 shows stress-strain curves obtained from the tensile tests for the FSW joint and the base metal. The yield and ultimate tensile strength of them were similar, although elongation of the FSW joint was slightly lower than that of the base metal. The fracture of the FSW joint occurred in the base metal, not in the welding region. As a result, it was revealed that a hundred percent of 


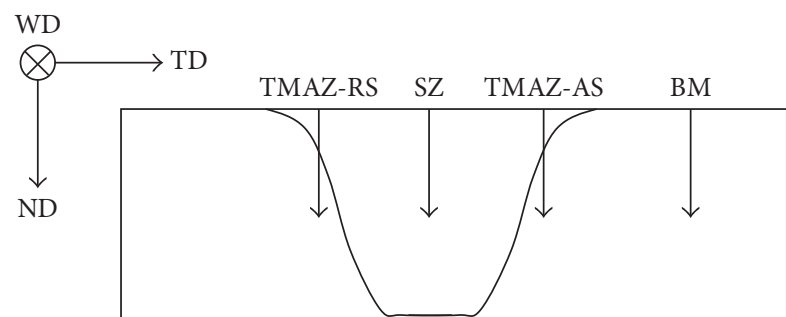

FIGURE 3: Schematic illustration of the residual stress measurement position.

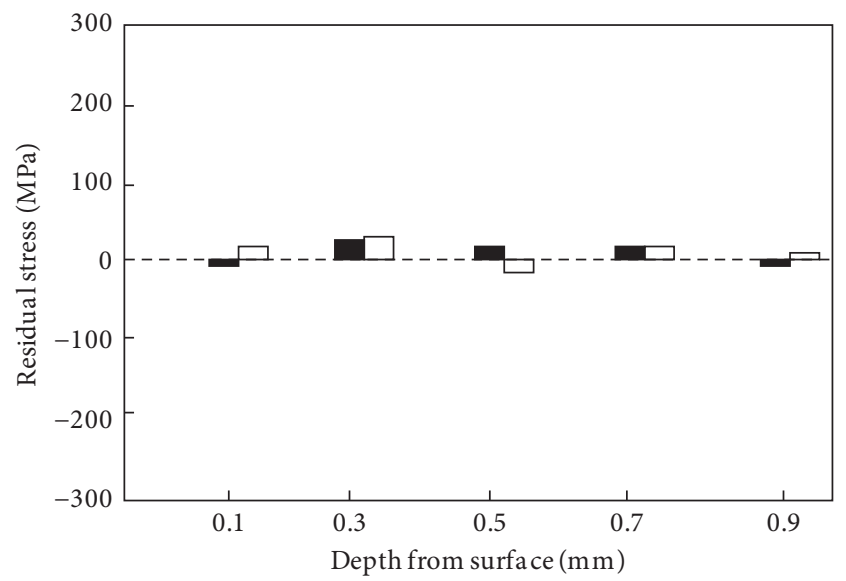

BM-TD

$\square$ BM-WD

Figure 4: Residual stress distribution of the base metal.

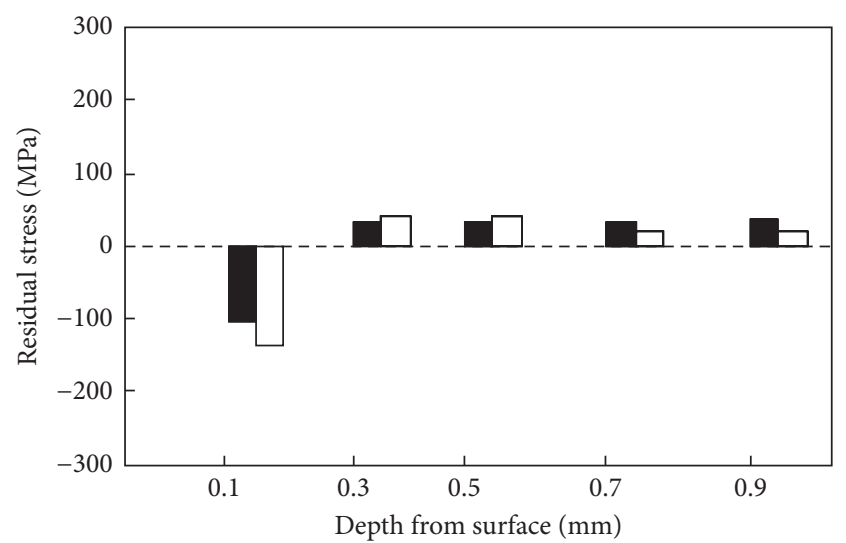

SZ-TD

$\square$ SZ-WD

Figure 5: Residual stress distribution of the stir zone.

joint efficiency could be obtained under the optimized process conditions, in case of SUS 409L stainless steel sheets.

The Charpy impact test results are shown in Figure 9. The impact properties were evaluated by measuring the crack initiation energy $\left(E_{i}\right)$, the crack propagation energy $\left(E_{p}\right)$, and the total energy $\left(E_{t}\right)$ absorbed up to the fracture. $E_{i}$ of the two specimens was almost the same. However, $E_{p}$ of

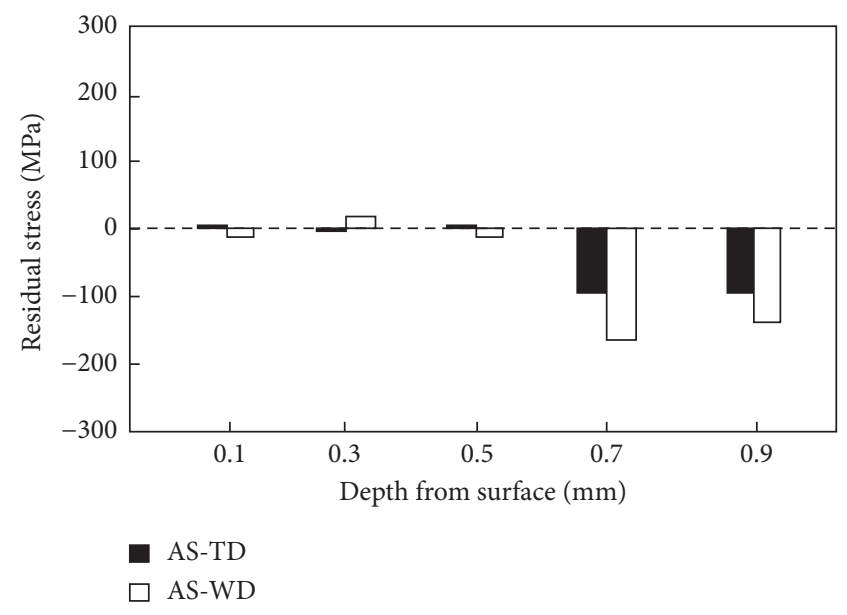

FIGURE 6: Residual stress distribution of the advancing side.

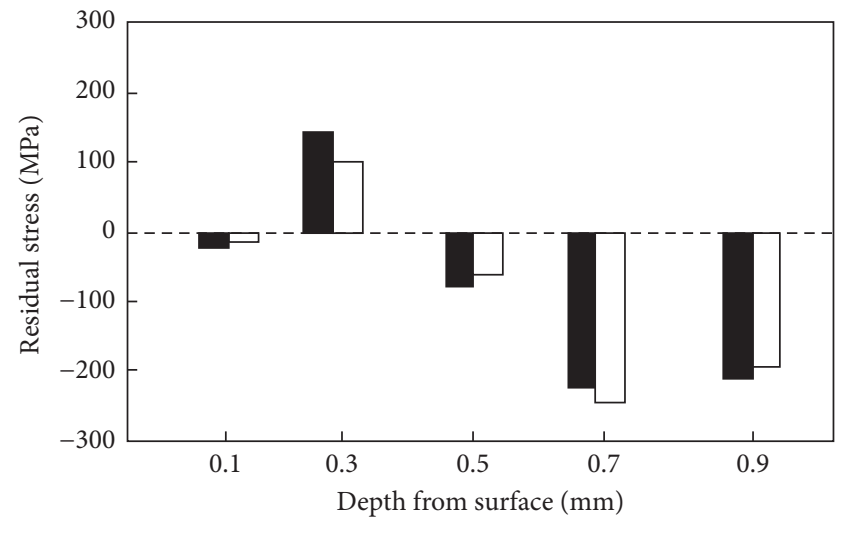

RS-TD

$\square$ RS-WD

Figure 7: Residual stress distribution of the retreating side.

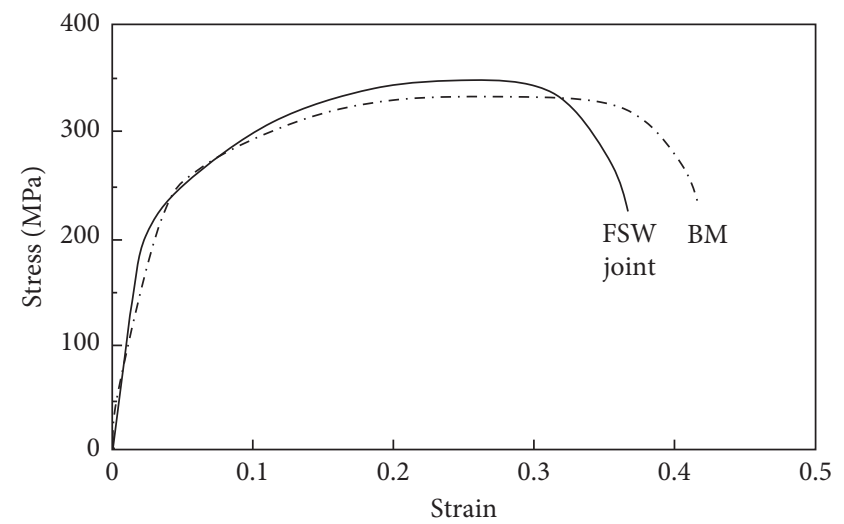

FIgURE 8: Stress-strain curves of the BM and FSW joints.

the FSW joint was higher than that of the base metal. This result is uncommon in welding fields. Generally, the impact properties of the welding joints manufactured by the conventional welding method such as arc and laser welding processes are inferior to the base metal. For this difference, the authors thought that the formation of ultrafine grains in 


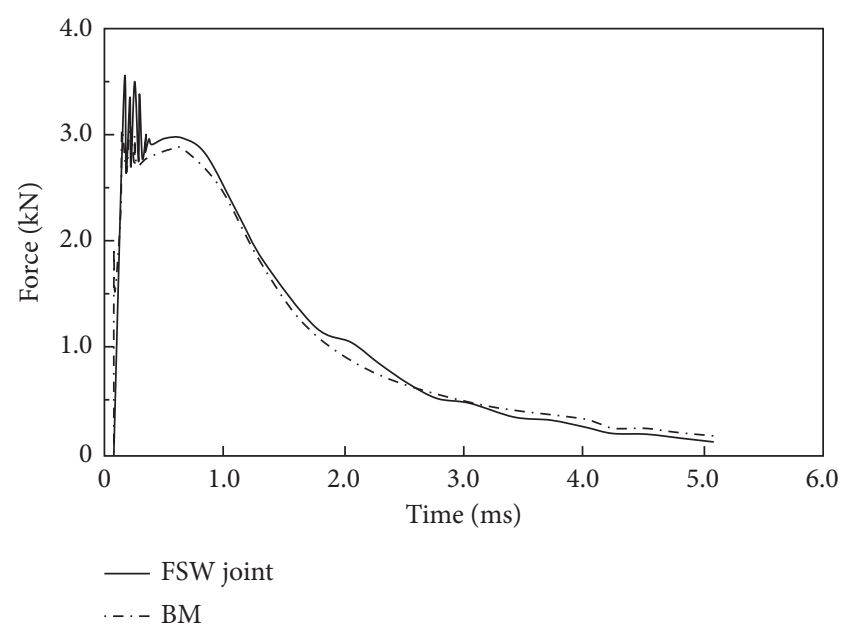

FIGURE 9: Force-time graphs and absorbed impact energy of the $\mathrm{BM}$ and FSW joints obtained by impact tests.

the stir zone, as shown in Figure 2, made an effect on the increase of the crack propagation energy. These results said that the impact properties superior to the base metal could be obtained by the optimized FSW process condition.

The fatigue properties of the FSW joints and the base metal are shown by S-N (stress-number) curves in Figure 10. The S-N curve of the FSW joint was identical to that of the base metal. For both the FSW joint and the base metal, it was found that the fatigue life is considered infinite when the maximum stress was loaded at the range of $40 \sim 80$ percent of the yield strength. The fatigue limit of the FSW joints manufactured by the present condition was about $150 \mathrm{MPa}$. These results indicate that good fatigue properties equivalent to that of the base metal could be obtained with optimized FSW process conditions in SUS 409L stainless steel sheets. Both the evolution of the characteristic microstructure and residual stress and their possible effects on the mechanical properties of the FSW joints were discussed in the following section.

\section{Discussion}

4.1. Residual Stresses Evolution in the FSW Joints. Residual stresses are stresses that exist in materials although external forces are not applied. To be specific, residual stresses are stresses that exist in structures remaining in the equilibrium state even after the original cause of the stresses has been removed. Residual stresses can occur through a variety of mechanisms including plastic deformations, temperature gradients during thermal cycle, or structural changes with phase transformation. The heat from welding may cause localized expansion, which is taken up during welding by either the molten metal or the placement of parts being welded. When the finished weld cools, fusion zone cools and contracts more than others. As a result, residual stresses are left in the joints manufactured by conventional welding methods which include fusion and coagulation. However, residual stresses are not formed if the sheets are heated with a uniform temperature distribution. In other words, residual

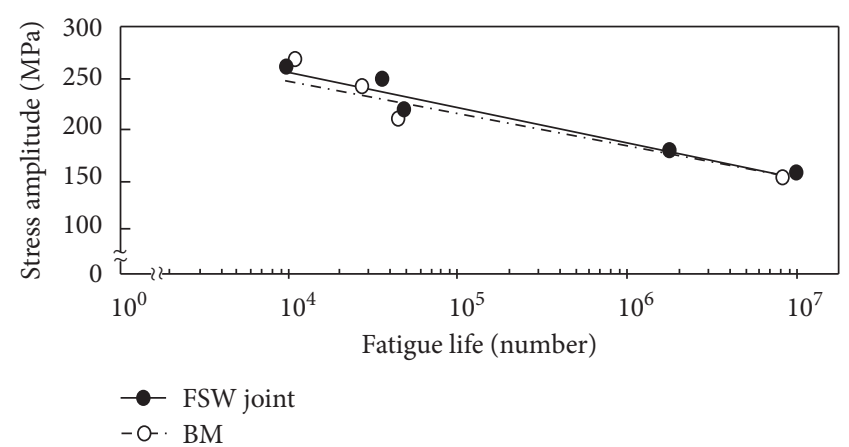

FIGURE 10: Stress-number curves of the BM and FSW joints obtained by fatigue tests.

stresses generated by welding are formed due to the nonuniform temperature distribution around the welding region. Therefore, the distribution of residual stresses is decided according to the temperature gradient in each direction. Additionally, the sum of tensile residual stress formed by solidification contraction and compressive residual stress generated by liquidation expansion always comes to zero because the structures with residual stress remain in the equilibrium state. Friction stir welding is one of the typical solid-state welding processes which does not involve melting. Therefore, the difference in the distribution of residual stresses could be occurred compare to the conventional welding processes. Based on the result of Figures 4-7, the formation behavior of the residual stress at the welding region during friction stir welding is shown in Figure 11. First, this study is going to consider formation of residual stress at stir zone. $\sigma_{x}$ which is residual stress of welding direction(length direction, $x$-direction) is formed as a result of inhomogeneous temperature distribution in width direction( $y$-direction). In the case of front A-A cross section (Figure 11(b)) close to the tool as a welding heat source, while the temperature around the weld line slightly rises, the temperature of section that remains away toward width direction does not rise. Therefore, around the weld line, the temperature tends to expand in the longitudinal direction, and in the section far from the weld line, the temperature remains intact. As a result, the forces in the $x$-direction are balanced as compression pressure near the weld line and tensile stress away from the weld line. In the case of B-B cross section that is the stir zone, compressive stresses created by initial heating get close to zero because the yield stress and the coefficient of elasticity become very small as the temperature in the stir zone reaches $70 \%$ degree of the melting temperature of the base metal. High temperature is enough to recrystallize strain-stored grains in the stir zone. Figure 12 shows the observation result of the microstructure at the time. As shown in Figures 12(a) and 12(b), while SZ is formed with equiaxed fine grains that is considered to be built by dynamic recrystallization during friction stir welding, TMAZ shows shear-deformed grain structure formed with mechanical metal flow. Stress built in the beginning of friction stir process can be assumed to be almost removed during the process of dynamic recrystallization that 


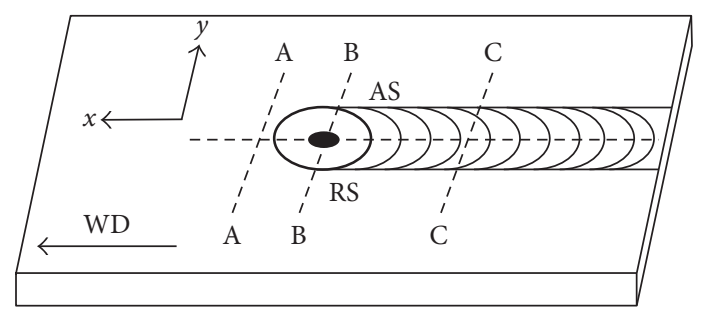

(a)
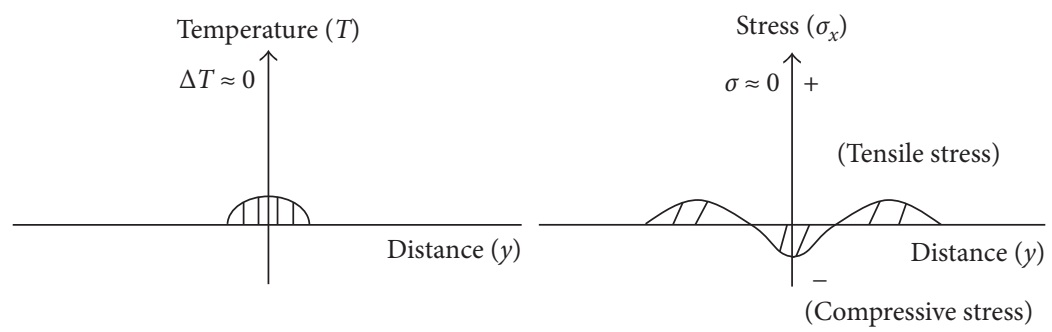

(b)
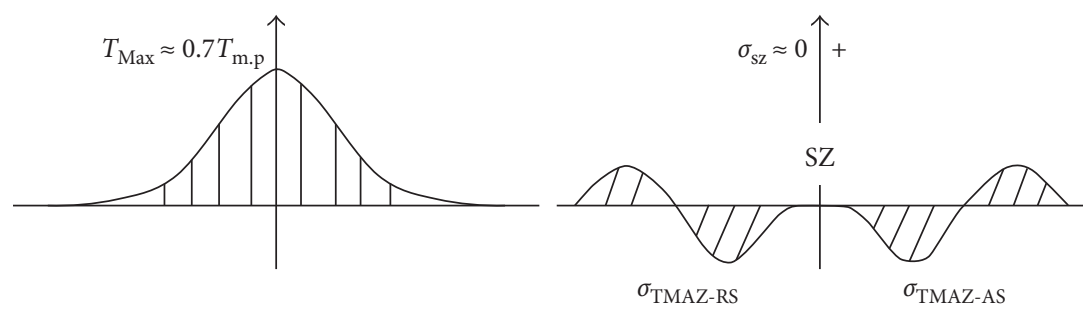

(c)
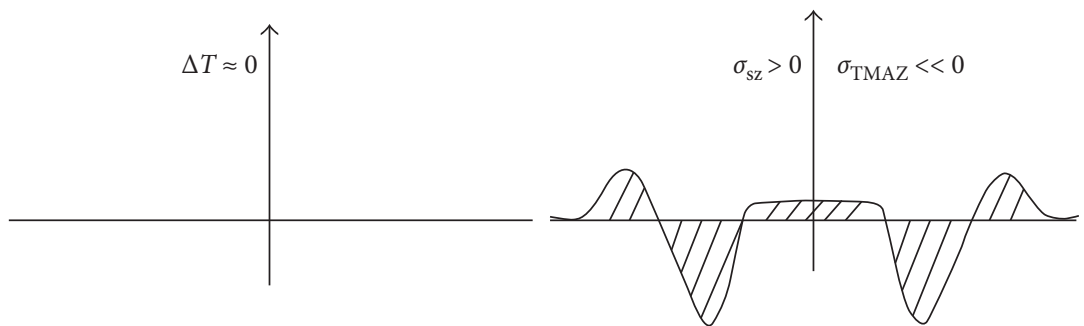

(d)

Figure 11: Temperature distribution and residual stress formation behavior during friction stir welding. (a) A-A: just before welding, (b) B$\mathrm{B}$ : during welding, and (c) C-C: after welding.

is occurred as a result of frictional heat and plastic flow. Compressive stress remains at TMAZ, which is the boundary of SZ and the base metal, due to thermal gradient and there will be tensile stress away from the weld line to reach equilibrium of force against compressive stress remaining near the boundary section. After passing the cross section $\mathrm{B}-\mathrm{B}$, heating process ends and cooling process begins around the weld line. When cooling process begins, minute tensile stress is considered to be formed at $\mathrm{C}$ - $\mathrm{C}$ cross section with the weld line as the center because contraction occurs elastically around the weld line. These results are in contradiction with the result that the tensile residual stress is considerably applied to the fusion zone in the conventional welding method. Stress is formed to satisfy the equilibrium of force in the region away from the weld line. The formation of residual stress at TMAZ which is the boundary of SZ and
$\mathrm{BM}$ is similar to that of $\mathrm{A}-\mathrm{A}$ section but the result shows that compressive stress is more developed. This is due to the synergistic effect of both thermal expansion by conductive heat from SZ and considerable compressive stress formed as a result of mechanical compression by tool's load. In friction stir welding section, unlike weld zone by conventional fusion welding, considerable compressive residual stress is built at TMAZ, and some of compressive residual stress and fine tension residual stress are formed in the surface area and the center area of SZ, respectively.

4.2. Relationship between Residual Stress and Mechanical Properties in the FSW Joints. In the field of fusion welding like arc, resistance, or laser, normally residual stress is formed about similar magnitude of yield stress of the base 


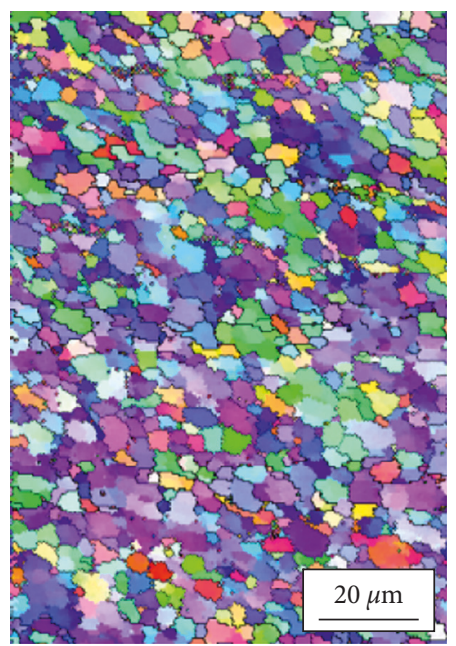

(a)

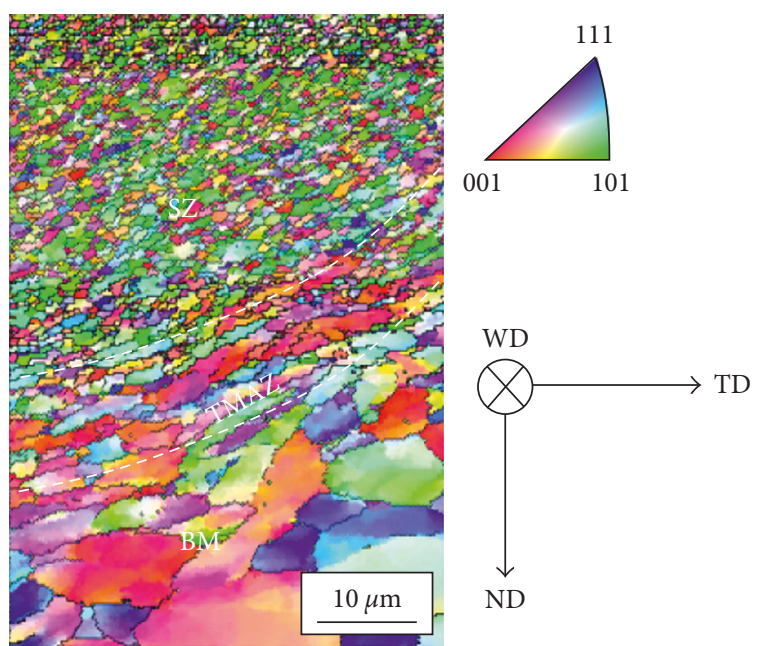

(b)

FIGURE 12: Inverse pole figure maps in (a) SZ and (b) TMAZ by the EBSD method.

metal. In other words, in traditional fusion welding, significant level of stress is acted before external force is added and this residual stress makes an effect on the mechanical properties of the welded structure. Akbari et al. experimentally measured and numerically analyzed the residual stress in 304L stainless steel welds by the TIG welding process. As a result, it reported that while tensile residual stress close to $200 \mathrm{Mpa}$ is formed in the fusion zone, there is a formation of corresponding compressive residual stress in the heat-affected zone. Generally, even if the welding process is optimized and there are no defects in the fusion zone, tensional residual stresses in the fusion zone significantly reduce the mechanical properties. On the contrary, as described in Figures 8-10, tensile strength and fatigue property of friction stir welded joints exceed the level of the base metal, and it is identified that fatigue characteristic is equal to the base metal. These results contradict with that of the welds manufactured by the traditional fusion welding process mentioned above. It is judged to be resulted from the difference in component of residual stress made from welding region by friction stir welding. In other words, the formation of compressive residual stress near the surface of stir zone, insignificant level of tension residual stress in stir zone, and significant level of compressive residual stress in thermomechanical affected zone contribute to maintaining the level of mechanical feature to an equal degree with the base metal. In case of welds made by traditional way of fusion welding, in which tensional residual stress built in fusion zone is close level of yield stress of its material, there is high possibility of plastic deformation due to cyclic compressive and tensile load or additional static tensile load. However, in case of friction stir welded joints where compressive residual stress as primary residual stress is formed in SZ and TMAZ, plastic deformation and rupture are being delayed when extra loads are applied. It is considered that the mechanical properties of FSW joints are improved due to both the formation of compressive residual stress in TMAZ and the ease of residual stress by dynamic recrystallization in SZ.

\section{Conclusion}

This study was performed to investigate both the residual stress distribution and the effect of the residual stress formed at the welding region on the mechanical properties of the friction stir welded joints with 409L stainless steel sheets. The conclusions obtained through the residual stress measurement with hole-drilling method; mechanical property evaluation including tensile test, Charpy impact test, and fatigue test; and microstructure observation are as follows:

(1) It has got no residual stresses to speak of at the center region of the stir zone because the stored stresses are released in the process of the dynamic recrystallization, while a small quantity of compressive residual stresses is formed at the surface region of the stir zone because of strong compression reaction by the tool shoulder.

(2) A considerable amount of compressive residual stresses is formed at the thermomechanical affected zone because of the synergy between the thermal expansion due to the heat conduction from the stir zone and the mechanical compression by the tool. The formation of residual stresses shows a similar tendency between the advancing side and the retreating side.

(3) Both the mitigation of residual stress in the stir zone and the formation of compressive residual stress in the thermomechanical affected zone contribute to the improvement of the mechanical properties of the friction stir welded joints.

\section{Conflicts of Interest}

The authors declare that they have no conflicts of interest. 


\section{Acknowledgments}

This work was supported by the Production Technology Commercialization Project (JB170007) of the Korea Institute of Industrial Technology. Part of the present study was also supported by the Project (KX170002) of the Production Technology for Commercialization of the Korea Industrial Complex Corporation.

\section{References}

[1] A. K. Lakshminarayanan, K. Shanmugam, and V. Balasubramanian, "Effect of welding processes on tensile and impact properties, hardness and microstructure of AISI 409M ferritic stainless joints fabricated by duplex stainless steel filler metal," Journal of Iron and Steel Research, International, vol. 16, no. 5, pp. 66-72, 2009.

[2] C. J. Lammi and D. A. Lados, "Effects of residual stresses on fatigue crack growth behavior of structural materials: analytical corrections," International Journal of Fatigue, vol. 33, no. 7, pp. 858-867, 2008.

[3] P. M. G. P. Moreira, M. A. V. de Figueiredo, and P. M. S. T. de Castro, "Fatigue behavior of FSW and MIG weldments for two aluminium alloys," Theoretical and Applied Fracture Mechanics, vol. 48, no. 2, pp. 169-177, 2007.

[4] A. F. Norman, V. Drazhner, and P. B. Prangnell, "Effects of welding parameters on the solidification microstructure of autogenous TIG welds in an Al-Cu-Mg-Mn alloy," Materials Science and Engineering: A, vol. 259, no. 1, pp. 53-64, 1999.

[5] J. Sun, X. Liu, Y. Tong, and D. Deng, "A comparative study on welding temperature fields, residual stress distributions and deformations induced by laser beam welding and $\mathrm{CO}_{2}$ gas arc welding," Materials \& Design, vol. 63, pp. 519-530, 2014.

[6] S. A. A. Akbari Mousavi and R. Miresmaeili, "Experimental and numerical analyses of residual stress distributions in TIG welding process for 304L stainless steel," Journal of Materials Processing Technology, vol. 208, no. 1-3, pp. 383-394, 2008.

[7] R. Unnikrishnan, K. S. N. Satish Idury, T. P. Ismail et al., "Effect of heat input on the microstructure, residual stresses and corrosion resistance of $304 \mathrm{~L}$ austenitic stainless steel weldments," Materials Characterization, vol. 93, pp. 10-23, 2014.

[8] M. P. Nascimento, C. C. Batista, B. A. Sorrija, and H. J. C. Voorwald, "Fatigue crack growth investigation on a maintenance welding repair applied on a high responsibility airframe," Procedia Materials Science, vol. 3, pp. 744-749, 2014.

[9] Q. Zhu, Y.-C. Lei, X.-Z. Chen, W.-J. Ren, X. Jub, and Y.-M. Ye, "Microstructure and mechanical properties in TIG welding of CLAM steel," Fusion Engineering and Design, vol. 86, no. 4-5, pp. 407-411, 2011.

[10] L. Zhang, J. Z. Lu, K. Y. Luo et al., "Residual stress, microhardness and tensile properties of ANSI 304 stainless steel thick sheet by fiber laser welding," Materials Science and Engineering: A, vol. 561, pp. 136-144, 2013.

[11] J. J. del Coz Díaz, P. Menéndez Rodríguez, P. J. García Nieto, and D. Castro-Fresno, "Comparative analysis of TIG welding distortions between austenitic and duplex stainless steels by FEM," Applied Thermal Engineering, vol. 30, no. 16, pp. 2448-2459, 2010.

[12] M. Anastassiou, M. Babbit, and J. Lebrun, "Residual stresses and microstructure distribution in spot-welded steel sheets: relation with fatigue behavior," Materials Science and Engineering: A, vol. 125, no. 2, pp. 141-156, 1991.
[13] T. Lienert and J. Lippold, "Improved weldability diagram for pulsed laser welded austenitic stainless steels," Science and Technology of Welding and Joining, vol. 8, no. 1, pp. 1-9, 2003.

[14] R. Mishra and Z. Ma, "Friction stir welding and processing," Materials Science and Engineering: R: Reports, vol. 50, no. 1-2, pp. 1-78, 2005.

[15] P. Moreira, T. Santos, S. Tavares, V. Richter-Trummer, P. Vilaca, and P. de Castro, "Mechanical and metallurgical characterization of friction stir welding joints of AA6061-T6 with AA6082-T6," Materials \& Design, vol. 30, no. 1, pp. 180-187, 2009.

[16] M. Ghosh, K. Kumar, S. Kailas, and A. Ray, "Optimization of friction stir welding parameters for dissimilar aluminum alloys," Materials \& Design, vol. 31, no. 6, pp. 3033-3037, 2010.

[17] V. M. Linton and M. I. Ripley, "Influence of time on residual stresses in friction stir welds in agehardenable $7 \mathrm{xxx}$ aluminium alloys," Acta Materialia, vol. 56, no. 16, pp. 43194327, 2008.

[18] G. Bussu and P. E. Irving, “The role of residual stress and heat affected zone properties on fatigue crack propagation in friction stir welded 2024-T351 aluminium joints," International Journal of Fatigue, vol. 25, no. 1, pp. 77-88, 2003.

[19] A. F. Golestaneh, A. Ali, and M. Zadeh, "Modeling the fatigue crack growth in friction stir welded joint of 2024-T351 Al alloy," Materials \& Design, vol. 30, no. 8, pp. 2928-2937, 2009.

[20] W. Han, A. Kimura, N. Tsuda et al., "Effects of mechanical force on grain structures of friction stir welded oxide dispersion strengthened ferritic steel," Journal of Nuclear Materials, vol. 455, no. 1-3, pp. 46-50, 2014. 


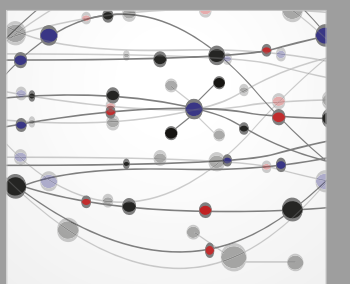

The Scientific World Journal
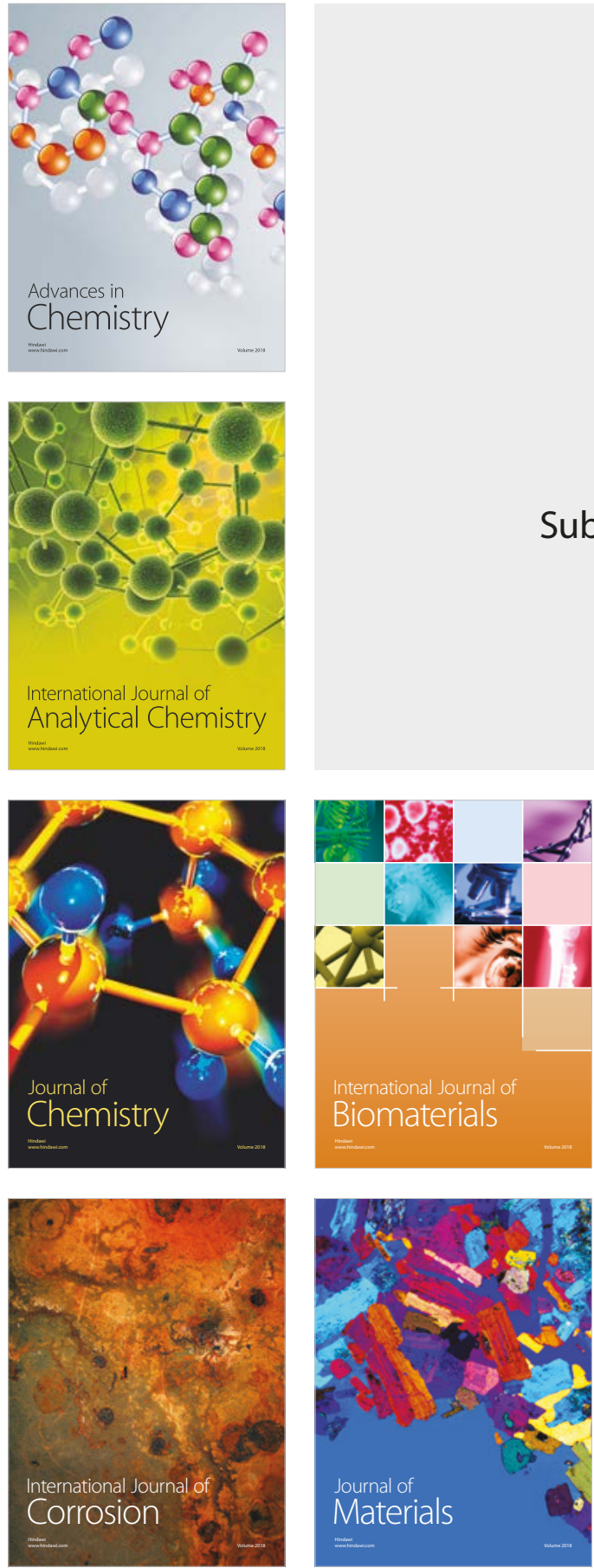

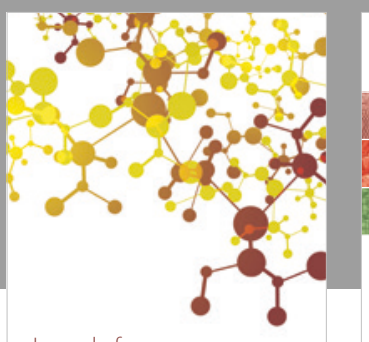

Journal of

Applied Chemistry
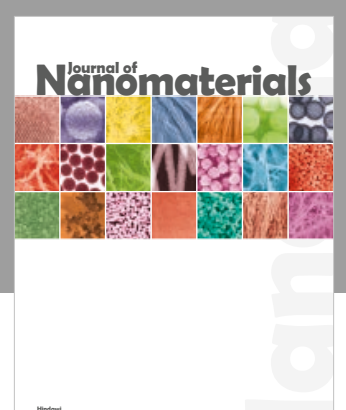

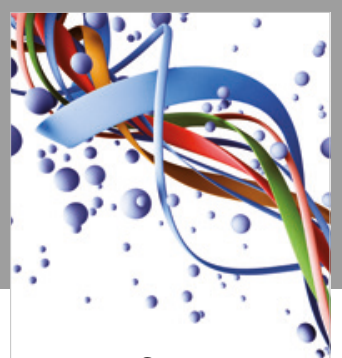

Scientifica

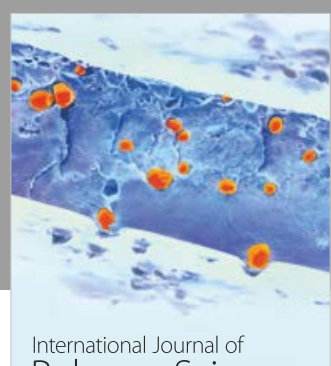

Polymer Science

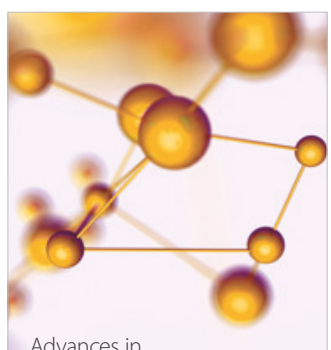

Physical Chemistry
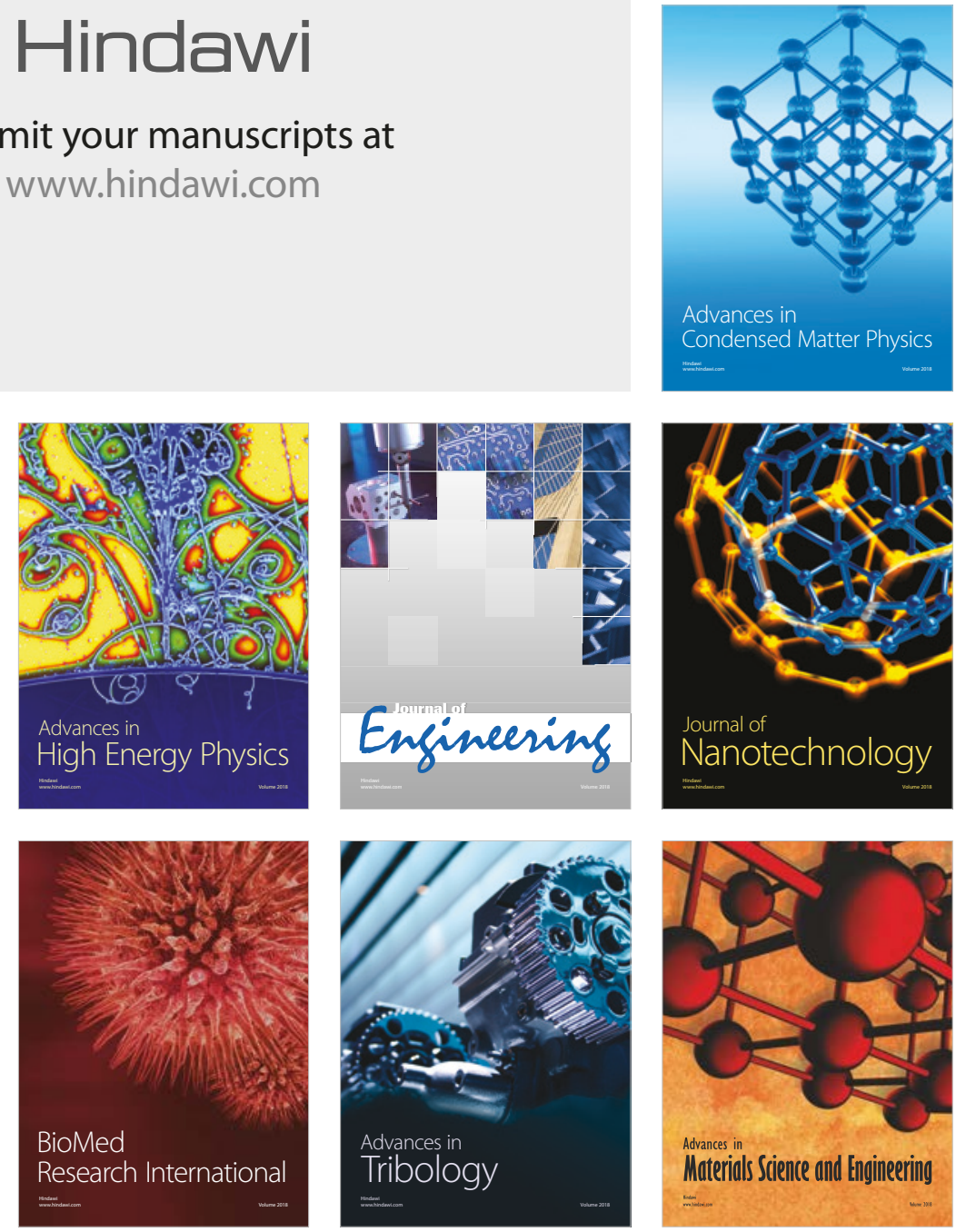